\title{
Endodontic treatment of mandibular incisors with an atypical anatomy
}

\author{
Tratamentul endodontic al incisivilor inferiori cu anatomie atipică
}

\begin{tabular}{c}
\hline Bogdan Mihai Gălbinaşu1, G. Tulus², I. Pătraşcu1, L.M. Nica ${ }^{3}$ \\
${ }^{1}$ Catedra de Tehnologia Protezelor şi Materiale Dentare, Facultatea de Medicină Dentară, \\
Universitatea de Medicină şi Farmacie „Carol Davila“, Bucureşti, România \\
${ }^{2}$ Cabinet privat endodonţie, Viersen, Germania \\
Universitatea de Medicină şi Farmacie „Victor Babeş“ Timişoara, România \\
Unina Odontoterapie-Endodonţie, Departamentul III, Facultatea de Medicin̆ Dentară, \\
\hline
\end{tabular}

\begin{abstract}
Related to endodontic literature, mandibular incisors seem to be infrequently treated from an endodontic point of view, excepting third molars.

The low percentage of endodontically treated mandibular incisors can be related to many causes, such as: low prosthetic value, difficult endodontic approach and, a more or less, good endodontic predictability due to intracanalar morphology.

Keywords: access cavity, atypical tooth anatomy ,dental operating microscope, intracanalar endodontic diagnostics, root filling

\section{REZUMAT}

Exceptând molarii de minte, incisivii inferiori par a fi trataţi endodontic cel mai rar, în conformitate cu datele existente în literatură. Cauzele procentajului scăzut al tratamentelor endodontice la această grupă de dinţi sunt multiple, probabil cele mai importante fiind valoarea protetică relativ scăzută, precum şi dificultăţile tratamentelor endodontice şi rata scăzută de succes, legate de morfologia deosebită a acestor dinţi.

Cuvinte cheie: cavitate de acces, anatomie atipică dentară, microscop dentar, diagnostic endodontic, obturaţie de canal
\end{abstract}

\section{NOTJIUNI DE ANATOMIE}

Din punct de vedere morfologic, incisivii mandibulari sunt cei mai mici dinţi de pe arcadă în ceea ce priveşte dimensiunea coroanei dentare. Rădăcina este ovală, cu diametrul maxim în sens vestibulo-lingual. Pe secțiune, sunt întâlnite diverse forme cu variabilitate destul de mare (ovală simplă, clepsidră, pişcot etc.).

Date despre anatomia complexă a sistemelor canalelor radiculare îşi au originea încă de jumătatea secolului 19 (6). Datele relevante despre anatomia complexă a sistemelor canalare se puteau obține, ceea ce este valabil şi în prezent, numai in vitro.
Diferenţele dintre metodele aşa-zise clasice şi cele moderne sunt reprezentate de tehnologia utilizată pentru vizualizarea sistemelor canaliculare, metodele clasice fiind distructive - de exemplu, transparentizarea prin demineralizarea rădăcinilor, respectiv a cementului şi a dentinei radiculare. Descrisă prima oară în anul 1911 de către Spaltenholz (28), transparentizarea dinţilor, respectiv a rădăcinilor, este utilizată, pe de-o parte, datorită valorii analitice şi, pe de altă parte, datorită prețului scăzut al investigației, inclusiv în prezent, evident, cu mici îmbunătățiri. În ceea ce priveşte analiza non-distructivă, există atât posibilitatea efectuării de microtomografii, cât şi de RMN (3); în momentul de 
față, se utilizează primordial microtomografii ale dinților extraşi. Rezoluția mare a microtomografelor moderne, de circa $20-23 \mu \mathrm{m}$, permite analize foarte exacte ale structurilor complexe ale sistemelor canaliculare radiculare, inclusiv ale istmurilor şi canalelor accesorii. Pe baza datelor culese, se fac reconstructii tridimensionale cu ajutorul unor softuri dedicate.

Analizele in vivo sînt reprezentate de evaluarea imaginilor radiologice, cu limitarea legată atât de rezoluția filmului dentar/folie sau senzor în cazul radiografiilor digitale, cât şi mai ales de imposibilitarea radiografierii în direcție mezio-distală, de evaluarea imaginilor obținute cu ajutorul tomografelor cu fascicul conic, care însă au o rezoluție semnificativ mai scăzută decât în cazul microtomografiilor, şi în urma evaluării clinice în cadrul tratamentelor endodontice (rezultate demne de luat în considerație în momentul de față ar fi numai în cazul tratamentelor efectuate sub microscop).

În urma analizelor efectuate cu ambele metode in vitro reiese că incisivii mandibulari au o structură a sistemului canalar substanțial mai complexă decât se poate bănui la o analiză radiologică.

Majoritatea dinților monoradiculari par a prezenta, cel puțin în cazul analizei imaginilor radiologice intraorale, o configurație relativ simplă a sistemului endodontic, respectiv un singur canal radicular. Această regulă nu se aplică în totalitate în cazul incisivilor inferiori, prevalența sistemelor complexe cu cel puțin două canale radiculare variind în cazul studiilor clasice, între $11 \%$ şi $44 \%$ $(4,8,13,18,23)$. Diferențele semnificative dintre datele publicate în literatură clasică par a se datora metodelor diferite de evaluare.

Un studiu relevant, bazat pe evaluarea a 100 de microtomografii făcute la incisivi mandibulari (15), arată că într-un procent de $28 \%$ sînt prezente două canale radiculare de tipul de configurație III conform clasificării descrise de Vertuci (31) (Fig. 1). La baza clasificării mai sus amintite stă evaluarea configurației morfologice a rădăcinii premolarului doi maxilar, utilizând metoda transparentizării, însă în literatură se pare că s-a implementat această clasificare pentru evaluarea tuturor rădăcinilor dentare. Configurația de tip III după Vertucci descrie varianta anatomică cu existența unui canal radicular principal, care porneşte de la nivelul camerei pulpare, se desparte în două canale separate, care apoi se unesc în apropiere de apex.

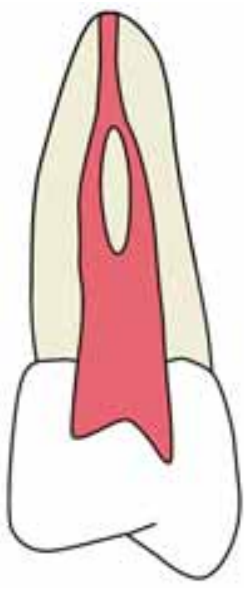

FIGURA 1. Reprezentare grafică a configurației Vertucci clasa III a sistemului endodontic
Coroană dentara este de dimensiuni reduse, cu lățime în sens mezio-distal la nivelul joncțiunii smalț-cement de circa $3 \mathrm{~mm}$ şi diametru maxim în sens vestibulo-lingual de circa $6 \mathrm{~mm}$ (14).

\section{Corelarea aspectelor anatomice cu terapia endodontică}

O evaluare a gradului de dificultate a tratamentelor endodontice pe categorii de dinți plasează grupul incisivilor inferiori imediat sub tratamentele efectuate la molari şi premolari inferiori cu mai mult de un canal radicular (32).

Particularitățile anatomice mai sus amintite trebuie luate în considerare în cazul planificării şi executării tratamentelor endodontice. Dimensiunile reduse ale coroanei dentare în sens mezio-distal reprezintă un factor de risc major pentru perforații în prima fază a tratamentului, respectiv prepararea cavităţii de acces endodontic (trepanare), mai ales în cazul în care dinții sînt înclinați către mezial sau distal. Acest risc creşte în cazul prezenței unor coroane de înveliş, aplicat în alt ax corono-radicular față de axul inițial. Pentru minimizarea riscului de perforație, este recomandabil să se utilizeze freze diamantate cu diametru de maximum $1 / 4$ din lățimea coroanei în sens mezio-distal, iar axa de trepanare trebuie să fie în axul rădăcinii. Locul de elecție pentru trepanare este în mod clasic în centrul treimii medii a suprafeței linguale, cu extindere în formă ovală către marginea incizală (11). Direcția frezei trebuie să aibă o înclinare către lingual, în concordanță cu axul de împlantare a rădăcinii, pentru a evita o perforație către vestibular. De asemenea, trebuie avut în vedere că profunzimea trepanării sporeşte odată cu vârstă pacientului, din cauza depunerii continue de dentină secundară. În cazul 
dinților cu abraziune majoră, punctul central al trepanării trebuie deplasat către marginea incizală (19), din cauza scurtării coroanei clinice dinspre incizal.

Trebuie menţionat că acest tip de trepanare, recomandat inclusiv în manuale universitare moderne, este în contradicție cu recomandarea accesului direct către canalul radicular sau canalele radiculare $(10,12)$. Din studiul mai sus menţionat, efectuat pe 279 de incisivi extraşi trepanați (19), reiese că, în $72,4 \%$ dintre cazuri, locul ideal de trepanare se află la nivelul muchiei incizale şi, în restul de $27,6 \%$ dintre cazuri, trepanarea ideală trebuie făcută vestibular de muchia incizală. Rezultatele unui alt studiu din anul 1999 demonstrează că accesul optim către sistemul în cazul trepanării incisivilor inferiori, cel puțin în cazul prezenței a două canale radiculare, este dinspre vestibular (17). Acelaşi studiu demonstrează şi faptul că, în cazul acestui tip de trepanare, sacrificiul de substanță dentară este diminuat față de trepanarea clasică. Trepanarea clasică prezintă diverse dezavantaje, cele mai importante fiind sacrificarea de substanţă dentară şi dificultatea găsirii şi instrumentării canalului lingual, $\mathrm{cu}$ consecințe nefavorabile asupra prognosticului (23).

În afară de aspectele anatomice mai sus menționate, dificultăţile sunt legate de imposibilitatea decelării predictibile a tipului de configurație a canalelor radiculare prin investigații radiologice convenţionale, chiar în cazul proiecțiilor excentrice. Într-un studiu efectuat pe 455 incisivi inferiori radiografiaţi în sens vestibulo-lingual şi în sens mezio-distal, se arată o prevalență de $13 \%$, respectiv 57 de cazuri, a prezenței a două canale radiculare în cazul evaluării radiografiilor în sens mezio-distal (20). Acest tip de proiecție nu este însă posibilă in vivo, proiecția normală ortoradială fiind în sens vestibulo-lingual, cu posibilitatea efectuării de proiecții excentrice de până la cca. $20^{\circ}$. Acest studiu demonstrează, pe de-o parte, acuratețea limitată a evaluării radiologice - investigațiile folosind metoda transparentizării sau microtomografiei demonstrează o incidență semnificativ mai mare a configurației de tip Vertucci III - şi, pe de altă parte, inexactitățile legate de rezultatele interpretării radiografiilor în proiecție vestibulo-linguală. În studiul mai sus menționat, în proiecție vestibulo-linguală au fost decelate două canale radiculare în numai 40 dintre cele 57 de cazuri, ceea ce reprezintă o marjă de eroare de circa $30 \%$. În celelalte 17 cazuri, s-a crezut că este un singur canal radicular, proiecția în sens mezio-distal demonstrând prezența a două canale.

Valoarea diagnostică superioară a tomografiei cu fascicul conic față de radiografiile convenţionale în ceea ce priveşte acuratețea evaluării morfologie radiculare $(1,7,29)$, precum şi decelarea ,rădăcinilor şi a canalelor adiționale“ (16) este neîndoielnică. O evaluare in vivo a prezenței a două canale radiculare prin analiza a 2.980 incisivi inferiori arată o incidență de circa 40\% (27). Cu toate avantajele tomografiei dentare, momentan nu este considerată ca fiind o investigație diagnostică preendodontică standard (30), din cauza gradului de iradiere semnificativ mai ridicat raportat la radiografiile intraorale, a rezoluția scăzute a multor tomografe „din piață“, a răspândirii limitate a tomografelor şi a prețului de cost ridicat al acestei investigații comparativ $\mathrm{cu}$ prețul radiografiilor intraorale.

În cazul interpretării radiografiilor preendodontice, există indicii care pot sugera existent a două canale radiculare (Fig. 2).

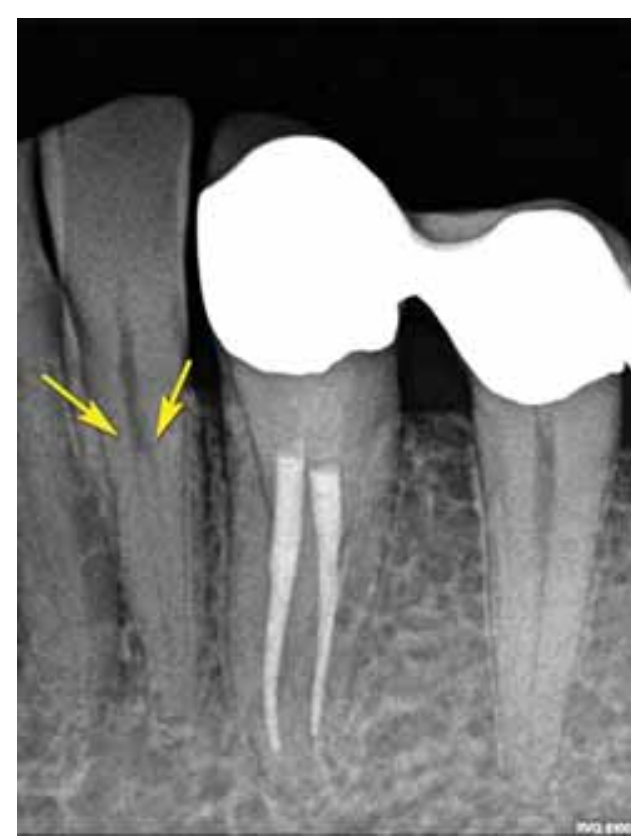

FIGURA 2. Imagine radiologică tipică pentru incisivi şi canini inferiori cu configurație clasa III a sistemului endodontic. Săgețile indică locul de separare a canalelor radiculare; imaginea radiologică la acest nivel creează senzația de canal radicular obliterat.

În proiecție ortoradială, în cazul existenței a două canale radiculare, se observă în general o dis- 
pariție bruscă a traiectului canalului radicular, la nivelul separării acestuia, imaginea radiologică sugerând un canal obliterat. În proiecție excentrică, se poate decela uneori punctul de separație a canalelor radiculare. În anumite situații, se poate vedea un spațiu parodontal dublat, ceea ce poate fi un indiciu al existenței a două canale radiculare sau a două rădăcini distincte, însă valoarea diagnostică a acestui indiciu este limitată de faptul că acelaşi aspect radiologic îl are şi prezența unui şanț în direcție cervico-apicală pe una dintre fețele aproximale ale rădăcinii (20).

Din punct de vedere clinic, utilizarea sistemelor de magnificație - precum lupe sau microscop dentar - creşte şansele de decelare a canalelor radiculare, şansele mai mari fiind în cazul utilizării microscopului dentar (36). Varianta optimă pentru decelarea ambelor canale radiculare este, aşadar, reprezentată de efectuarea tratamentului endodontic sub microscop dentar, de preferință cu iluminare cu xenon $(2,33)$.

\section{CAZ CLINIC}

La o pacientă în vârsta de 54 ani, cu stare de sănătate bună, s-a hotărât în anul 2005 efectuarea de tratamente endodontice la incisivii inferiori în scop protetic. Necesitatea tratamentelor endodontice a apărut în urma şlefuirii şi paralelizării bonturilor pentru protezarea mobilizabilă telescopată (Fig. 3 şi Fig. 4). Analiză imaginilor radiologice ale dinților 31 şi 32 arată o întrerupere a traiectului canalului radicular la circa 2-3 mm sub nivelul limbusului alveolar la dintele 31 şi la circa 4-5 mm sub nivelul limbusului alveolar la dintele 32 . O întrerupere a liniei de continuitate a canalului radicular se poate observa şi la dintele 33. În această situaţie, se poate pleca, conform celor descrise mai sus, de la premisa că aceşti dinți prezintă două canale radiculare, probabil de tipul configuraţiei de clasă III Vertucci. Acest fapt, coroborat cu faptul că incidența structurii identice bilaterale este de $69,8 \%$ la incisivii centrali inferiori şi de $68,7 \%$ la incisivii laterali inferiori (27), duce la concluzia că şi incisivii de pe partea contralaterală au cu o probabilitate mare un sistem canalar de tipul Vertucci III. Această premisă trebuie să se reflecte şi în strategia planificării şi efectuării tratamentelor endodontice.

Tratamentul a fost efectuat sub anestezie locoregională şi izolare absolută a câmpului operator cu ajutorul digii dentare, sub control vizual continuu utilizând un microscop dentar cu iluminare coxială cu lampă de xenon de 180 W (ProErgo, Zeiss, Oberkochen). Trepanarea a fost făcută la cei patru incisivi începând de la nivelul treimii superioare a feței linguale şi extinsă în formă ovală pînă la nivelul marginii incizale a bonturilor. Luând în considerare vârsta pacientei, au fost folosite freze diamantate cilindrice cu diametru de $0,8 \mathrm{~mm}$, astfel încât diametrul maxim în sens mezio-distal să nu depăşească 1 mm şi, în acelaşi timp, să se obțină un acces direct către camera pulpară şi intrarea în canalul radicular principal $(12,21)$. După deschiderea camerei pulpare, s-a continuat prepararea în sens apical cu freze sferice de uz endodontic pentru micromotor de dimensiuni ISO 010 pînă la nivelul intrării în canalul radicular. Turația utilizată a fost de 5.000
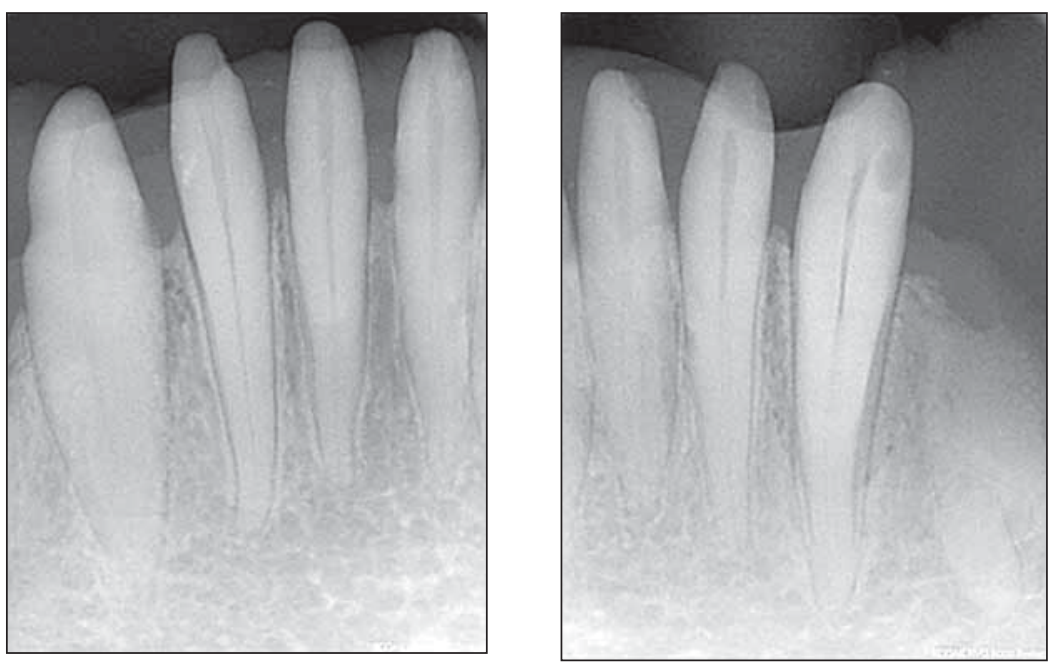

FIGURA 3 şi FIGURA 4. Radiografii diagnostice preendodontice ale incisivilor 32-42 
de rotații pe minut. Rumeguşul dentinar a fost îndepărtat cu ajutorului irigantului folosit $(\mathrm{NaOCl} 3 \%)$ la intervale de 3-5 secunde, imediat după irigare urmând uscarea cavităților pentru un control vizual optim. După decelarea canalului principal, s-a încercat cateterizarea canalelor utilizând ace de mână de tip K de dimensiune ISO 010. La fiecare dintre canale, a fost percepută o, ,piedică“ la circa 5-7 mm sub nivelul intrării în canale. Această piedică este la nivelul septului de separare a canalelor radiculare. În această situație, s-a trecut la lărgirea treimii coronare a canalului radicular principal până la nivelul istmului cu instrumentar rotativ cu conicitate mare FlexMaster 35.06 şi 30.06 (VDW, München) în tehnică crown-down $(5,24,34)$, utilizând un motor cu limitare a momentului de torsiune pentru fiecare instrument utilizat Endo IT professional (VDW, München) (35).

După irigare intensivă cu $\mathrm{NaOCl}, \mathrm{s}-\mathrm{a}$ încercat cu ajutorul instrumentelor endodontice manuale precurbate de dimensiune ISO 010 investigarea prezenței unei separări a canalului pricipal. În acest scop, s-a efectuat cateterizarea canalului principal cu instrumentarul mai sus amintit, iniţial în contact cu peretele lingual, iar la următoarea introducere a acului în contact cu peretele vestibular. Cateterizarea s-a făcut sub control electrometric utilizând Raypex 4 (VDW, München), fiind decelate câte două canale radiculare (Fig. 5). După determinarea electrometrică a constricției apicale şi instrumentarea manuală pînă la ISO 15, s-au efectuat radiografii de control cu ace pe canal (Fig. 6) în proiecție excentrică pentru dinții 41 şi 42. Imaginea radiologică arată poziționarea vîrfului instrumentelor la

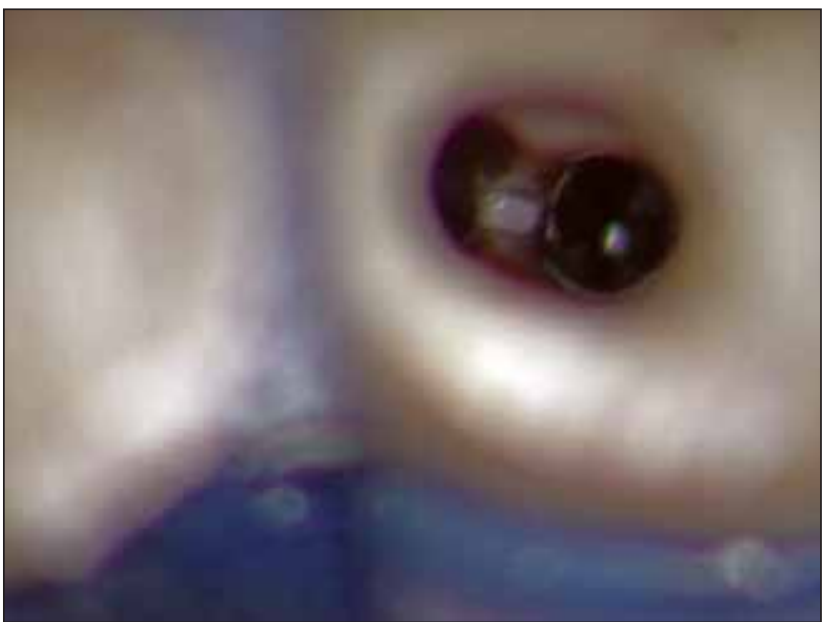

FIGURA 5. Imagine clinică sub microscop cu orificiile de intrare în canalele radiculare la nivelul separării canalelor

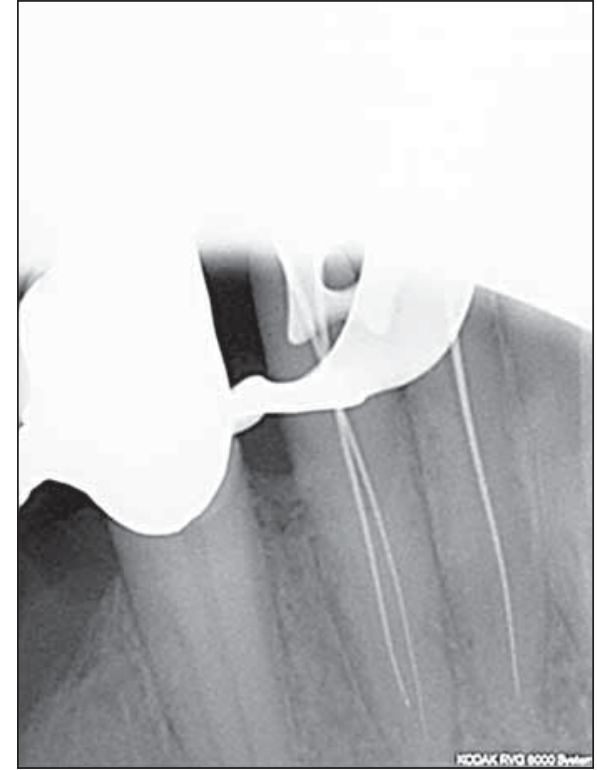

FIGURA 6. Radiografie de control a lungimii de lucru cu ace pe canale la dinții 41,42

circa $2 \mathrm{~mm}$ de apexul radiologic, ceea ce este în concordanță cu distanța medie statistică dintre constricția apicala şi apexul radiologic (22). Având în vedere similitudinea acurateței determinării electrometrice şi radiologice a lungimii de lucru (9), existând o corelare între determinarea electrometrică a lungimii de lucru şi imaginea radiologică în cazul dinţilor 41 şi 42, s-a renunțat la efectuarea unei noi radiografii pentru dinţii 31 şi 32, din considerente de diminuare a iradierii pacientei. Instrumentarea finală a canalelor radiculare s-a efectuat rotativ, utilizând în continuare sistemul FlexMaster, atât datorită abilităţii acestui sistem în păstrarea configurației inițiale a canalelor radiculare, cât şi datorită instrumentării mai rapide comparativ cu cea manuală (25).

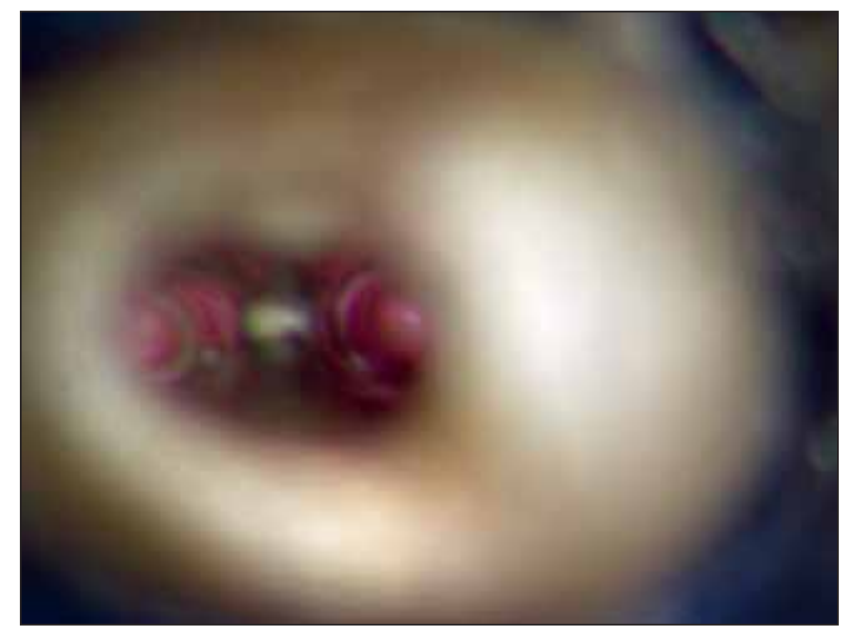

FIGURA 7. Imagine clinică a obturației de canal cu gutapercă termoplastificată 

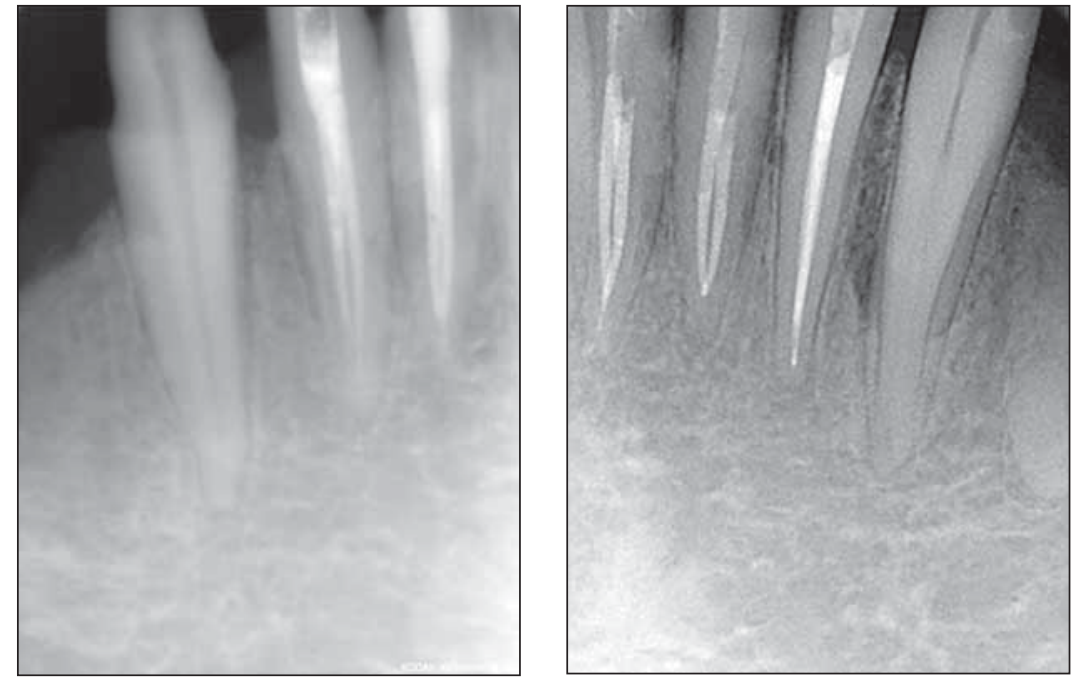

FIGURA 8 şi FIGURA 9. Radiografii de control după obturația radiculară la dinții 32-42

După instrumentarea finală a canalelor radiculare, toți cei patru dinți prezentând câte două canale după tipul Vertucci III, s-a efectuat obturarea canalelor radiculare prin compactare verticală termoplastică după tehnică descrisă de Schilder (26), utilizând System B (SybronEndo, Orange, USA) pentru sigilarea apicală (down-pack) şi Obtura (Obtura Spartan Endodontics, Algonquin, USA) pentru injectarea gutapercii termoplastificate (Fig. 7). Sigilarea cavităților de acces a fost făcută utilizând material compozit după aplicarea adezivă a unor ştifturi intracanalare din fibră de sticlă (DT Light, VDW, München).

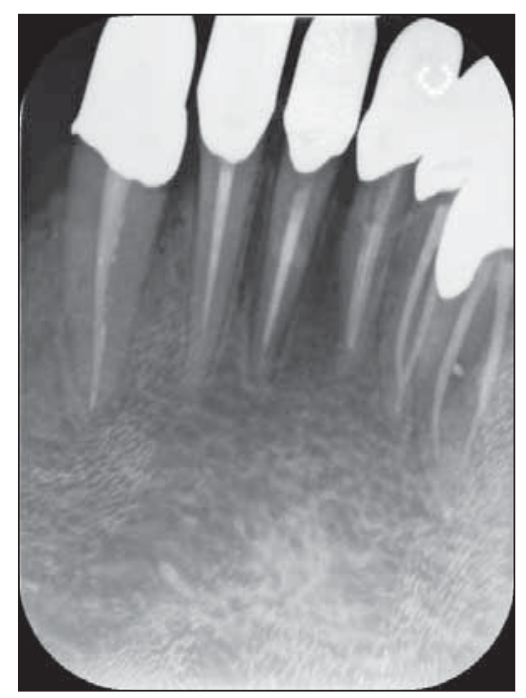

FIGURA 10. Radiografie de control postendodontic 14 ani după tratamentul dinților 32-42 şi 6 ani după tratamentul endodontic al dinților 33 şi 43.
Radiografiile de control după obturațiile de canal demonstrează obturarea optimă a canalelor radiculare a celor patru incisivi (Fig. 8, Fig. 9).

În urma evaluării tratamentelor mai sus, descrise prin controalele regulate, atât clinice, cât şi radiologice, pe o perioadă de 14 ani, nu se constată apariția unor procese patologice, ceea ce relevă corectitudinea tratamentului endodontic în concordanță cu configurația sistemului endodontic complex. În radiografia de control, efectuată la 14 ani după tratament (Fig. 10), se constată că şi cei doi canini mandibulari, trataţi endodontic ulterior, prezintă un sistem endodontic complex cu câte două canale radiculare.

Conflict of interest: none declared Financial support: none declared 


\section{BIBLIOGRAFIE}

1. Abella F., Teixidó L.M., Patel S., Sosa F., Duran-Sindreu F., Roig M. Cone-beam Computed Tomography Analysis of the Root Canal Morphology of Maxillary First and Second Premolars in a Spanish Population. Journal of Endodontics 2015; 41: 1241-1247

2. Arnold M. The dental microscope - basis for new and proven methods in root canal treatment. ENDO - Endod Pract Today 2009: 205-214

3. Baumann M. Die räumliche Darstellung des Endodonts. Hanser, München 1995

4. Benjamin K.A., Dowson J. Incidence of two root canals in human mandibular incisor teeth. Oral Surg Oral Med Oral Pathol 1974; 38: 122-126

5. Bergmans L., van Cleynenbreugel J., Wevers M., Lambrechts P. Mechanical root canal preparation with $\mathrm{NiTi}$ rotary instruments: Rationale, performance and safety. Status report for the American Journal of Dentistry. Am J Dent 2001; 14: 324-333

6. Carabelli G. Systematisches Handbuch der Zahnheilkunde. Baumüller und Seidel, Wien 1844

7. Cotton T.P., Geisler T.M., Holden D.T., Schwartz S.A., Schindler W.G. Endodontic applications of cone-beam volumetric tomography. Journal of Endodontics 2007; 33: $1121-1132$

8. Green D. Double canals in single roots. Oral Surg Oral Med Oral Pathol 1973; 35: 689-696

9. Hoer D., Attin T. The accuracy of electronic working length determination. Int Endod J 2004; 37: 125-131

10. Ingle J.I., Himel V.T., Hawrish C.E. et al. Endodontics. Endodontic cavity preparation. Elsevier, Ontario 2002

11. Janik J.M. Access cavity preparation. Dent Clin North Am 1984; 28: 809-818

12. LaTurno S.A., Zillich R.M. Straight-line endodontic access to anterior teeth. Oral Surg Oral Med Oral Pathol 1985; 59: 418-419

13. Laws A.J. Prevalence of canal irregularities in mandibular incisors: a radiographic study. N Z Dent J 1971; 67: 181-186

14. Lee M.M, Rasimick B.J., Turner A.M., Shah R.P., Musikant B.L., Deutsch A.S. Morphological measurements of anatomic landmarks in pulp chambers of human anterior teeth. Journal of Endodontics 2007; 33: 129-131

15. Leoni G.B., Versiani M.A., Pécora J.D., Damião de Sousa-Neto M. Micro-computed tomographic analysis of the root canal morphology of mandibular incisors. Journal of Endodontics 2014; 40: 710-716

16. Levin A., Shemesh A., Katzenell V., Gottlieb A., Ben Itzhak J., Solomonov M. Use of Cone-beam Computed Tomography during Retreatment of a 2-rooted Maxillary Central Incisor: Case Report of a Complex Diagnosis and Treatment. Journal of Endodontics 2015; 41: 2064-2067

17. Logani A., Singh A., Singla M., Shah N. Labial access opening in mandibular anterior teeth--an alternative approach to success. Quintessence Int 2009; 40: 597-602

18. Madeira M.C., Hetem S. Incidence of bifurcations in mandibular incisors. Oral Surg Oral Med Oral Pathol 1973; 36: 589-591

19. Mauger M.J., Waite R.M., Alexander J.B., Schindler W.G. Ideal endodontic access in mandibular incisors. Journal of Endodontics 1999; 25: 206-207
20. Nattress B.R., Martin D.M. Predictability of radiographic diagnosis of variations in root canal anatomy in mandibular incisor and premolar teeth. Int Endod J 1991; 24: 58-62

21. Nielsen C.J., Shahmohammadi K. The Effect of MesioDistal Chamber Dimension on Access Preparation in Mandibular Incisors. Journal of Endodontics 2005; 31: 88-90

22. Palmer M.J., Weine F.S., Healey H.J. Position of the apical foramen in relation to endodontic therapy. J Can Dent Assoc (Tor) 1971; 37: 305-308

23. Rankine-Wilson R.W., Henry P. The Bifuccated Root Canal In Lower Anterior Teeth. J Am Dent Assoc 1965; 70: 1162-1165

24. Schäfer E., Lohmann D. Efficiency of rotary nickel-titanium FlexMaster instruments compared with stainless steel hand K-Flexofile--Part 2. Cleaning effectiveness and instrumentation results in severely curved root canals of extracted teeth. Int Endod J 2002; 35: 514-521

25. Schäfer E., Schulz-Bongert U., Tulus G. Comparison of hand stainless steel and nickel titanium rotary instrumentation: a clinical study. Journal of Endodontics 2004; 30: 432-435

26. Schilder H. Filling root canals in three dimensions. Dent Clin North Am 1967: 723-744

27. Shemesh A., Kavalerchik E., Levin A. et al. Root Canal Morphology Evaluation of Central and Lateral Mandibular Incisors Using Cone-beam Computed Tomography in an Israeli Population. Journal of Endodontics 2018; 44: 51-55

28. Spaltenholz Werner. Über das Durchsichtigmachen von menschlichen und tierischen Präparaten, nebst Anhang: Über Knochenfärbung. On transparentized human and animal specimens, including notes on bone staining. S. Hirzel, Leipzig 1911

29. Tyndall D.A., Kohltfarber H. Application of cone beam volumetric tomography in endodontics. Tex Dent J 2012; 129 : $1195-1208$

30. Use of cone-beam computed tomography in endodontics Joint Position Statement of the American Association of Endodontists and the American Academy of Oral and Maxillofacial Radiology. Oral Surg Oral Med Oral Pathol Oral Radiol Endod 2011; 111: 234-237

31. Vertucci Frank J. Root canal morphology and its relationship to endodontic procedures. Endodontic Topics 2005; 10: 3-29

32. Weine F.S. Endodontic therapy. Mosby, St. Louis (Mo.) 1996

33. Xu Q., Liu H.-Y., Ling J.-Q., Luo D.-F. Clinical management of mandibular incisors with multiple root canals using dental operating microscope. Hua Xi Kou Qiang Yi Xue Za Zhi 2008; 26: 522-525

34. Yared G.M., Bou Dagher F.E., Machtou P. Failure of ProFile instruments used with high and low torque motors. Int Endod J 2001; 34: 471-475

35. Yared G.M., Bou Dagher F.E., Machtou P. Influence of rotational speed, torque and operator's proficiency on ProFile failures. Int Endod J 2001; 34: 47-53

36. Yoshioka T., Kobayashi C., Suda H. Detection rate of root canal orifices with a microscope. Journal of Endodontics 2002; 28: 452-453 